\title{
An efficient method for stable protein targeting in grasses (Poaceae): a case study in Puccinellia tenuiflora
}

Yuanyuan $\mathrm{Bu}^{1 \dagger}$, Mengqing Zhao ${ }^{1 \dagger}$, Bo Sun ${ }^{1}$, Xinxin Zhang ${ }^{1}$, Tetsuo Takano ${ }^{2}$ and Shenkui Liu ${ }^{{ }^{*}}$

\begin{abstract}
Background: An efficient transformation method is lacking for most non-model plant species to test gene function. Therefore, subcellular localization of proteins of interest from non-model plants is mainly carried out through transient transformation in homologous cells or in heterologous cells from model species such as Arabidopsis. Although analysis of expression patterns in model organisms like yeast and Arabidopsis can provide important clues about protein localization, these heterologous systems may not always faithfully reflect the native subcellular distribution in other species. On the other hand, transient expression in protoplasts from species of interest has limited ability for detailed sub-cellular localization analysis (e.g., those involving subcellular fractionation or sectioning and immunodetection), as it results in heterogeneous populations comprised of both transformed and untransformed cells.

Results: We have developed a simple and reliable method for stable transformation of plant cell suspensions that are suitable for protein subcellular localization analyses in the non-model monocotyledonous plant Puccinellia tenuiflora. Optimization of protocols for obtaining suspension-cultured cells followed by Agrobacterium-mediated genetic transformation allowed us to establish stably transformed cell lines, which could be maintained indefinitely in axenic culture supplied with the proper antibiotic. As a case study, protoplasts of transgenic cell lines stably transformed with an ammonium transporter-green fluorescent protein (PutAMT1;1-GFP) fusion were successfully used for subcellular localization analyses in P. tenuiflora.
\end{abstract}

Conclusions: We present a reliable method for the generation of stably transformed $P$. tenuiflora cell lines, which, being available in virtually unlimited amounts, can be conveniently used for any type of protein subcellular localization analysis required. Given its simplicity, the method can be used as reference for other non-model plant species lacking efficient regeneration protocols.

Keywords: Non-model plant, Suspension-cultured cells, Green fluorescent protein (GFP), Agrobacterium, Subcellular localization

\section{Background}

The subcellular localization of plant proteins is highly correlated with their functions, and as such, is a particularly relevant aspect of functional studies. In many cases, subcellular localization can be predicted in silico based on the primary protein sequence by exploiting the conservation

\footnotetext{
* Correspondence: shenkuiliu@nefu.edu.cn

${ }^{\dagger}$ Equal contributors

'Key Laboratory of Saline-Alkali Vegetation Ecology Restoration in Oil Field (SAVER), Ministry of Education, Alkali Soil Natural Environmental Science Center (ASNESC), Northeast Forestry University, Hexing Road No. 26, Xiangfang District, Harbin City, Heilongjiang Province 150040, China

Full list of author information is available at the end of the article
}

of signal peptides and motifs responsible for protein targeting to different cell compartments [1]. Despite recent advances in improving the accuracy of algorithms for prediction [2,3], experimental validation of predicted localization is still the golden standard to obtain reliable functional information.

Transient gene expression assays allow for rapid and high-throughput analyses of plant genes, and thus have become widely used for characterization studies of gene function. Accordingly, several methods for transient gene expression have been developed, such as polyethylene glycol-mediated protoplast transfection [4], biolistic bombardment [5], and Agrobacterium-mediated transient assays 
[6]. In addition, stable plant transgenic lines (particularly Arabidopsis) expressing epitope-tagged or otherwise modified genes offer advantages in terms of ensuring a sustainable supply of plant material with homologous protein expression, the potential for mutant complementation, as well as the ability to conduct a global-scale examination throughout all tissues and cell types. Although the commonly used floral dip procedure can also be used toward this end, this procedure is more time consuming and laborious as it requires the maintenance and growth of the transgenic plants to maturity, which can take up to several weeks or longer.

All these methods have specific advantages and disadvantages depending on the experimental question and setup at hand. In general, however, heterologous expression systems, either transient or stable, have the major drawback of being prone to experimental artifacts. There are several challenges associated with the above-described method for determining protein subcellular localization in non-model plants, including the difficulty in obtaining transgenic plant lines and to express a protein and determine its subcellular localization in the original plant cells, because an efficient regeneration system has not yet been established for several wild plant species. To date, gene function analysis of wild plant species has been conducted using the model plant Arabidopsis or in yeast [7-9]; however, because these are heterologous systems, even when they successfully express certain wild plant genes, the localization of the encoded proteins might not be representative of localization in the native species [10]. Therefore, in order to best study the subcellular localization of wild plant species proteins, an effective homologous expression system needs to be established. While stable transformation of gametes or regeneration of whole plants from transformed somatic cells is routinely achieved in model plant species (e.g., by floral dipping in Arabidopsis thaliana), for most non-model species, the lack of suitable protocols and the phenomenon of regeneration recalcitrance make the obtainment of whole-plant transformants an arduous task. To circumvent this problem, we here propose a method for protein subcellular localization analyses that does not rely on obtaining whole-plant transformation, but instead focuses on the Agrobacterium-mediated stable transformation of cells in suspension-cultures (Figure 1). Plant suspension-cultured cells, a proven physiological and versatile cell system, are widely used in plant biology as a convenient tool for highthroughput functional analysis, and have also been successfully used for genetic analyses [11-16]. Here, we present a reliable and highly efficient method for stable gene expression in Puccinellia tenuiflora suspensioncultured cells by Agrobacterium-mediated transformation. We applied this method to express an endoplasmic reticulum-green fluorescent protein (ER-GFP) fusion

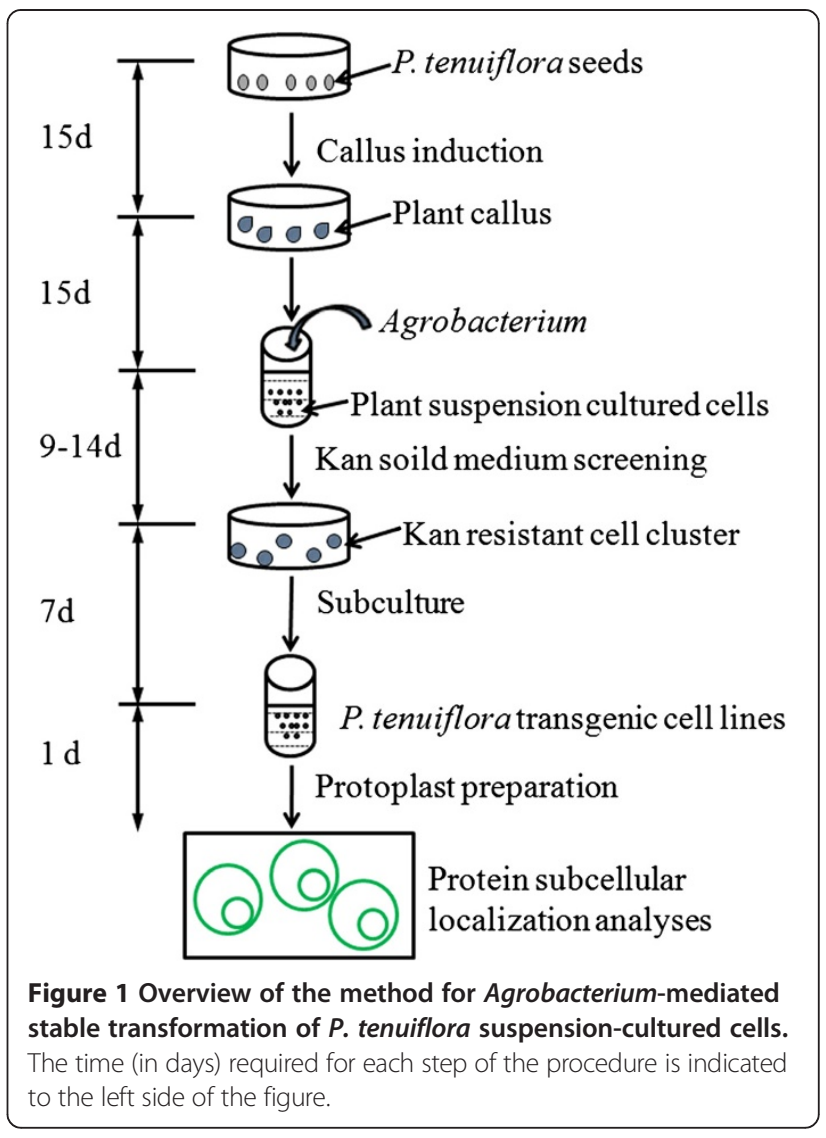

protein in $P$. tenuiflora, a grass halophyte with extreme tolerance to alkaline soils $(\mathrm{pH} \approx 10)$.

\section{Methods}

\section{Materials and preparations}

Wild P. tenuiflora seeds and Agrobacterium tumefaciens harboring the plasmid $p B I 121-E R-G F P$ were provided from the Alkali Soil Natural Environment Science Center of Northeast Forestry University, Anda practice base, Harbin, China. This plasmid contains 499 amino acids from the PutAMT1;1 ammonium transporter from P. tenuiflora, which has been previously demonstrated to be localized at the nucleus periphery in correspondence with the ER and the plasma membrane [17]. P. tenuiflora plants were collected from an area of alkaline soil in Northeast China (Heilongjiang Province). No specific permissions were required for these activities, as sampling did not involve any endangered or protected species.

\section{Callus induction and subculture training}

P. tenuiflora seeds were soaked in distilled water at $4{ }^{\circ} \mathrm{C}$ for 1-2 d. After the seeds were dried and soaked in $75 \%$ alcohol for $1 \mathrm{~min}$, they were rinsed 3-4 times with sterile water, then with $10 \%$ sodium hypochlorite for $30 \mathrm{~min}$, and finally with sterile water 3-5 times. The calli were induced on the disinfected dry seeds after inoculation in the 
induction medium, which comprised Murashige and Skoog (MS) medium containing $0.5 \mathrm{~g} / \mathrm{L}$ proline, $0.5 \mathrm{mg} / \mathrm{L}$ glutamic acid, $30 \mathrm{~g} / \mathrm{L}$ sucrose, $2.0 \mathrm{mg} / \mathrm{L}$ 2,4-dichlorophenoxyacetic acid (2,4-D), and $0.8 \%$ agar $(\mathrm{pH} 5.8)$ at $25^{\circ} \mathrm{C}$ under illumination of $80 \mu \mathrm{mol} /\left(\mathrm{m}^{2} \cdot \mathrm{s}\right)$ for $12 \mathrm{~h} / \mathrm{d}$. Calli were obtained after 2 weeks. Weakly yellow, loose calli were selected for subculture training.

\section{Establishment of the system of $P$. tenuiflora suspension-cultured cell system}

The selected calli were cultured at $22^{\circ} \mathrm{C}$ with shaking at $120 \mathrm{rpm}$ in the dark. After culturing for 1, 3, 5, 7, 9, 11, $13,15,17,19$, or $21 \mathrm{~d}$, the evenly suspended cells were harvested. Simultaneously, for subculture training, $10 \mathrm{~mL}$ of suspension-cultured cells (dry weight approximately $40 \mathrm{mg}$ ) were inoculated in liquid MS medium with different nutrient conditions: 1) different types of nitrogen nutrients, including 1/2 MS (i.e., half concentration of regular MS), MSN (i.e., half the ammonium nitrate amount of MS), MSK (i.e., half the potassium nitrate amount), MSE (i.e., additional $0.5 \mathrm{mg} / \mathrm{L}$ glutamic acid), MSP (i.e., additional $0.5 \mathrm{~g} / \mathrm{L}$ proline), MSPE (i.e., $0.5 \mathrm{mg} / \mathrm{L}$ glutamic acid and $0.5 \mathrm{~g} / \mathrm{L}$ proline), $\mathrm{MSCH}$ (i.e., $0.6 \mathrm{~g} / \mathrm{L}$ casein acid hydrolysate), and MSPECH (i.e., $0.5 \mathrm{mg} / \mathrm{L}$ glutamic acid, $0.5 \mathrm{~g} / \mathrm{L}$ proline, and $0.6 \mathrm{~g} / \mathrm{L}$ casein acid hydrolysate); all the different media contained $2.0 \mathrm{mg} / \mathrm{L}$ 2,4-D, and $30 \mathrm{~g} / \mathrm{L}$ sucrose $(\mathrm{pH}=5.8) ; 2)$ different concentrations of sucrose, including $2.0 \mathrm{mg} / \mathrm{L} \mathrm{2,4-D,} \mathrm{and} 0,10$, $20,25,30,35,40$, or $50 \mathrm{~g} / \mathrm{L}$ sucrose at $\mathrm{pH}=5.8$; 3) the same hormone at different concentrations: $\mathrm{MSPECH}+0$, 1.0, 2.0, 3.0, or $4.0 \mathrm{mg} / \mathrm{L} \mathrm{2,4-D} \mathrm{and} 30 \mathrm{~g} / \mathrm{L}$ sucrose at $\mathrm{pH}=5.8 ; 4)$ different $\mathrm{pH}$ : MSPECH $+2.0 \mathrm{mg} / \mathrm{L} \mathrm{2,} \mathrm{4-D} \mathrm{and}$ $30 \mathrm{~g} / \mathrm{L}$ sucrose at $\mathrm{pH}=3.8,4.8,5.8,6.8,7.8,8.8,9.8$, or 10.8. All media were tested at $22 \pm 1^{\circ} \mathrm{C}$ with shaking at $120 \mathrm{rpm}$ in the dark. After culturing for $15 \mathrm{~d}$, the suspension cultures $(50 \mathrm{~mL})$ were centrifuged at $2000 \mathrm{rpm}$ for $5 \mathrm{~min}$, then dried at $70^{\circ} \mathrm{C}$ for $24 \mathrm{~h}$ and weighed; this process was repeated three times.

\section{Effect of acetosyringone (AS) on transformation}

Three-day-old P. tenuiflora suspension-cultured cells were used to test the effects of AS on the transformation process. AS (100 mg/L) was added to the culture medium to create our subculture, while the cells in the culture medium without AS were used as the control.

\section{Isolation of protoplasts from $P$. tenuiflora suspension-cultured cells}

Five-day-old P. tenuiflora suspension-cultured cells $(5 \mathrm{~mL})$ were centrifuged at $800 \mathrm{rpm}$ for $5 \mathrm{~min}$, and the precipitated cells were washed and centrifuged again at $800 \mathrm{rpm}$ for $5 \mathrm{~min}$. The newly precipitated cells were weighed and incubated in $0.05 \mathrm{mM}$ MES ( $\mathrm{pH} 5.8$ ) containing $2 \%$ cellulose enzyme, $1 \%$ pectinase, $0.2 \mathrm{M} \mathrm{CaCl}_{2} \cdot 2 \mathrm{H}_{2} \mathrm{O}$, and $0.6 \mathrm{M}$ mannitol for 3-4 h at $28^{\circ} \mathrm{C}$ with gentle shaking. After the enzymatic digestion, the cells were centrifuged at $100 \mathrm{rpm}$ for $5 \mathrm{~min}$ and the supernatant was discarded. The cells were resuspended in $2 \mathrm{mM}$ MES ( $\mathrm{pH}$ 5.7) containing $154 \mathrm{mM} \mathrm{NaCl}, 125 \mathrm{mM} \mathrm{CaCl}_{2}$, and $5 \mathrm{mM} \mathrm{KCl}$ for $30 \mathrm{~min}$. Protoplasts were harvested by centrifugation at $1000 \mathrm{rpm}$ for $5 \mathrm{~min}$, washed three times using the resuspension solution, and then solubilized in the solution containing $0.16 \mathrm{M}$ mannitol and $0.02 \mathrm{M} \mathrm{CaCl}_{2} \cdot 2 \mathrm{H}_{2} \mathrm{O}$.

\section{Transformation of $P$. tenuiflora suspension-cultured cells}

Two-week-old suspension-cultured $P$. tenuiflora cells $(5 \mathrm{~mL})$ were inoculated into $20 \mathrm{~mL}$ of freshly modified MS medium containing $100 \mathrm{mg} / \mathrm{L}$ AS. After $3 \mathrm{~d}$, the cells were co-cultured with Agrobacterium at optical density at $600 \mathrm{~nm}\left(\mathrm{OD}_{600}\right)$ of $0.5,1.0,1.5$, or 2.0 with shaking at $120 \mathrm{rpm}$ and maintained at $22^{\circ} \mathrm{C}$ in the dark for $3 \mathrm{~d}$. Then, the cells were filtered over nylon nets and washed with $200 \mathrm{mg} / \mathrm{L}$ cefotaxime (Cef) in sterile water. After being transferred to the liquid medium for $24 \mathrm{~h}$, $1 \mathrm{~mL}$ suspension-cultured cells was inoculated into the modified MS medium containing $2.0 \mathrm{mg} / \mathrm{L} \mathrm{2,4-D,} 30 \mathrm{~g} / \mathrm{L}$ sucrose $(\mathrm{pH}=5.8)$, additional $0,25,50,75$, or $150 \mathrm{mg} / \mathrm{L}$ kanamycin (Kan), and 0, 100, 200, 300, 400, or $500 \mathrm{mg} / \mathrm{L}$ Cef at $25^{\circ} \mathrm{C}$ in the dark. Subsequently, the cluster of cells was transferred into $50 \mathrm{~mL}$ of liquid medium containing Kan and Cef and incubated at $22^{\circ} \mathrm{C}$ with shaking at $120 \mathrm{rpm}$ in the dark for $9-14 \mathrm{~d}$ to obtain the transgenic suspension-cultured cells. Finally, the cells were harvested and dried at $70^{\circ} \mathrm{C}$ for $24 \mathrm{~h}$. The dry weight was measured three times.

\section{GFP fluorescence observation}

Green fluorescence of $P$. tenuiflora transgenic cells was observed using a stereomicroscope (Olympus, SZX9, Japan). The detection of the GFP signals was carried out using a laser-scanning confocal imaging system (Olympus Fluoview, FV500, Japan).

\section{Results and discussion}

Most of the currently available methods for protein subcellular localization can be readily applied to the majority of model plant species such as Arabidopsis and tobacco, which could, in principle, lend themselves as heterologous recipients for localization studies of proteins from nonmodel plant species $[18,19]$. However, the relatively high failure rates reported in studies adopting such heterologous approaches (e.g., for Arabidopsis proteins expressed in tobacco) indicate that homologous expression systems are preferable whenever possible $[10,20]$. The lack of established regeneration protocols for the large majority of non-model plant species hinders the application of whole-plant stable transformation methods for protein subcellular localization studies, which rely mainly on 
transient transformation approaches. The latter methods, however, are limited with respect to the level of detail to which localization can be assessed, as subcellular fractionation or sectioning and immunodetection methods cannot be applied, thus seriously preventing analyses of functional characterization of genes in non-model species. Therefore, adaptation of methods for the stable transformation of cell cultures that are currently applied mainly for functional studies [21,22] to protein subcellullar localization analyses would provide two main advantages for cases dealing with non-model species: (1) the faithful representation of native localization patterns that are typical of homologous systems, and (2) the versatility, robustness, and virtually unlimited amount of material available for characterizing stable transformation methods. As a case study for the development of such an approach, we chose to use $P$. tenuiflora, a non-model halophite grass belonging to the Poaceae family that has been the subject of several previous studies owing to its ability to grow in soils with extremely high salinity and $\mathrm{pH}$ [23-26]. Given that $P$. tenuiflora is recalcitrant to regeneration, it can be conveniently used as a representative case for the proof of concept of the novel method.

\section{Establishment of suspension cell lines of $P$. tenuiflora}

To establish $P$. tenuiflora suspension-cultured cells, a callus was induced by dedifferentiation of mature $P$. tenuiflora seeds. In brief, among the calli with different morphologies induced on the seeds of $P$. tenuiflora, we chose a yellow, loose callus (Figure 2A) with a clear nucleus and without visible intercellular aggregations (Figure 2B) for subculture. Unlike the standard method used for filtering rice [21], dispersed cells were obtained by slight grinding of the callus. The obtained cell clusters were mixed with liquid culture medium and cultured for $15 \mathrm{~d}$. The culture conditions were optimized to produce the suspension-cultured cell system of P. tenuiflora as described below.

\section{Optimization of the liquid medium}

We optimized the liquid medium in terms of concentration of sucrose (Figure 3A), amounts of 2,4-D (Figure 3B), $\mathrm{pH}$ (Figure 3C), and types of nitrogen nutrients (Figure 3D) added in a total volume of $50 \mathrm{~mL}$ of MS medium. After 15 $\mathrm{d}$ of cultivation, the dry weight of the harvested cells was measured. The dry weight of $P$. tenuiflora suspensioncultured cells was found to be highest in MSPECH medium ( $\mathrm{pH}=5.8)$ containing $30 \mathrm{~g} / \mathrm{L}$ sucrose and $2 \mathrm{mg} / \mathrm{L}$ of 2,4-D (Figure 3), which was thus chosen as the optimum medium for the culture of $P$. tenuiflora suspension-cultured cells.

\section{Growth performance of $P$. tenuiflora suspension-cultured cells}

In order to understand the growth dynamics of $P$. tenuiflora suspension-cultured cells, we characterized their dry weight in terms of culturing time under the optimized conditions. Figure 4A shows the growth curve of the $P$. tenuiflora suspension-cultured cells at different growth stages. Suspension-cultured cells $(10 \mathrm{~mL})$ were inoculated into $50 \mathrm{~mL}$ of MS medium, and the dry weight of the suspension was determined to be approximately $40 \mathrm{mg}$. After $5 \mathrm{~d}$ of cultivation, the growth rate increased and stabilized at $\sim 15 \mathrm{~d}$ of cultivation, after which the cells started to show signs of aging, thus prejudicing further tests. Furthermore, as shown in Figure 4B, the cells were well dispersed, and the small cell clusters presented inclusions and uniform appearance during the $5-15 \mathrm{~d}$ of cultivation. Our results showed that during the 5-15 d of cultivation, the cultured cells were stable and reached a high dry weight, which were suitable conditions to perform Agrobacterium transformation.

\section{P. tenuiflora suspension-cultured cells are a stable genetic transformation system}

The Agrobacterium-mediated transformation was used to establish the genetic transformation system of the

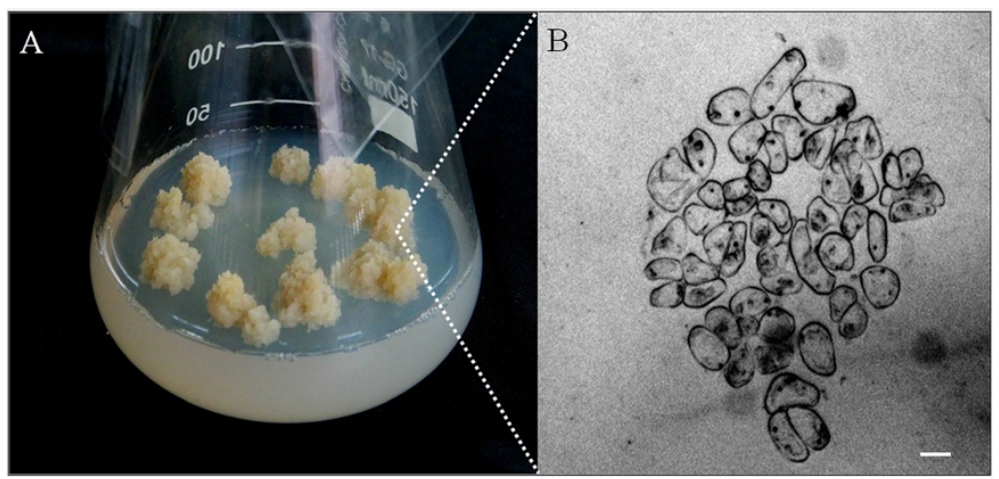

Figure 2 Callus induction in P. tenuiflora. (A) A friable and yellow callus of $P$. tenuiflora suspension cultures. (B) Magnified image of the single cells, obtained using a microscope, showing no visible intercellular aggregations and clear nuclei. Scale bar $=10 \mu \mathrm{m}$. 


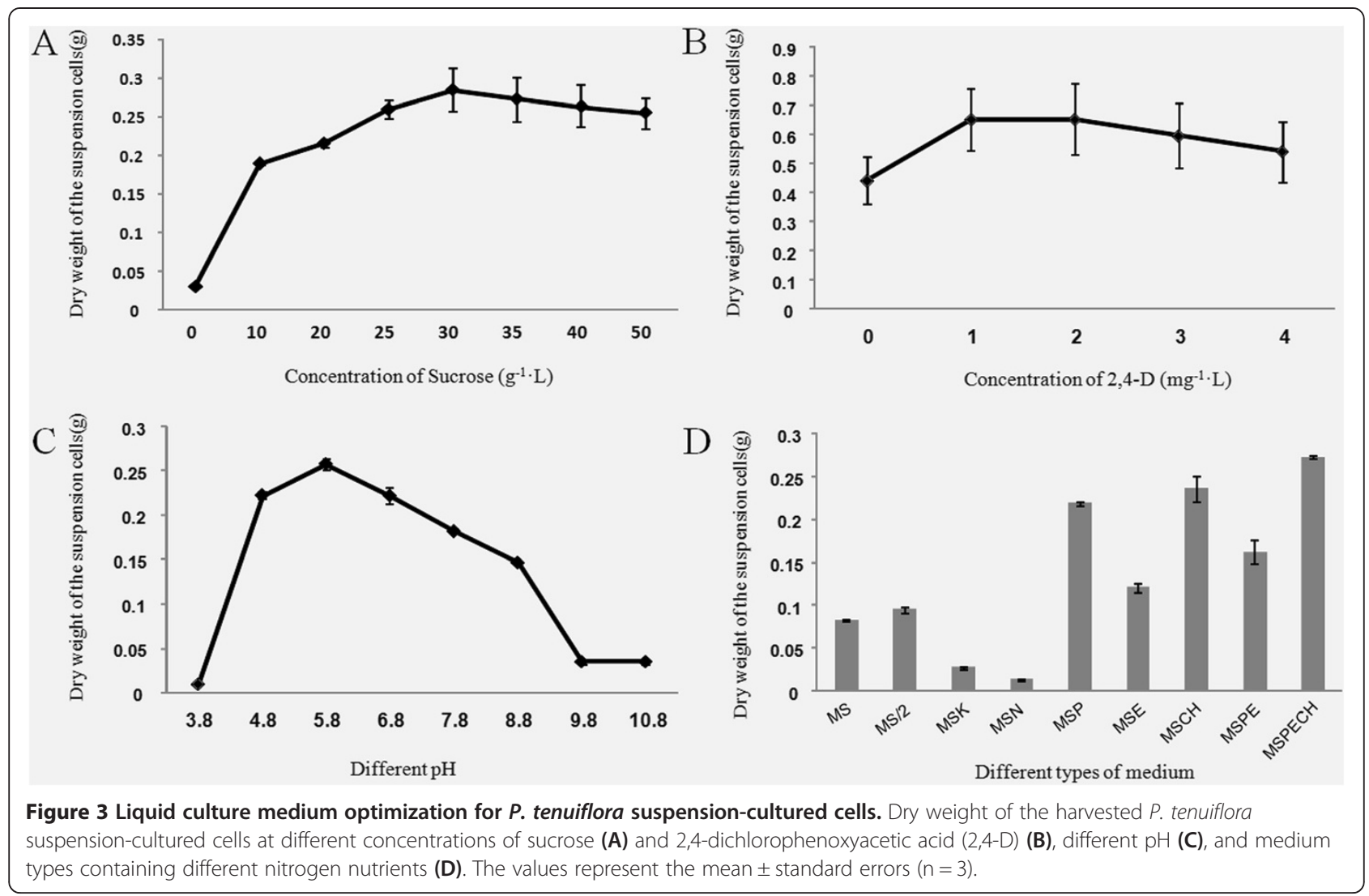

P. tenuiflora suspension-cultured cells. The pBI121-ERGFP plasmid was used to transform the $P$. tenuiflora suspension-cultured cells. The transgenic cells were screened on a solid medium containing the appropriate marker. To ensure high transformation efficiency, the Agrobacterium concentration, AS effect, co-culture time during transformation, and working concentrations of Kan and Cef were optimized as described below.

\section{Agrobacterium concentration}

Considering that Agrobacterium concentration can affect the transformation efficiency, four different concentrations of Agrobacterium were tested: $\mathrm{OD}_{600}=0.5,1.0,1.5$, and 2.0. Although Kan-resistant cell clusters grew at Agrobacterium concentrations of an $\mathrm{OD}_{600}$ of $0.5,1.0$, and 1.5, the growth of the cell clusters was negatively affected at higher concentration $\left(\mathrm{OD}_{600}=2.0\right)$. Therefore, we suggest
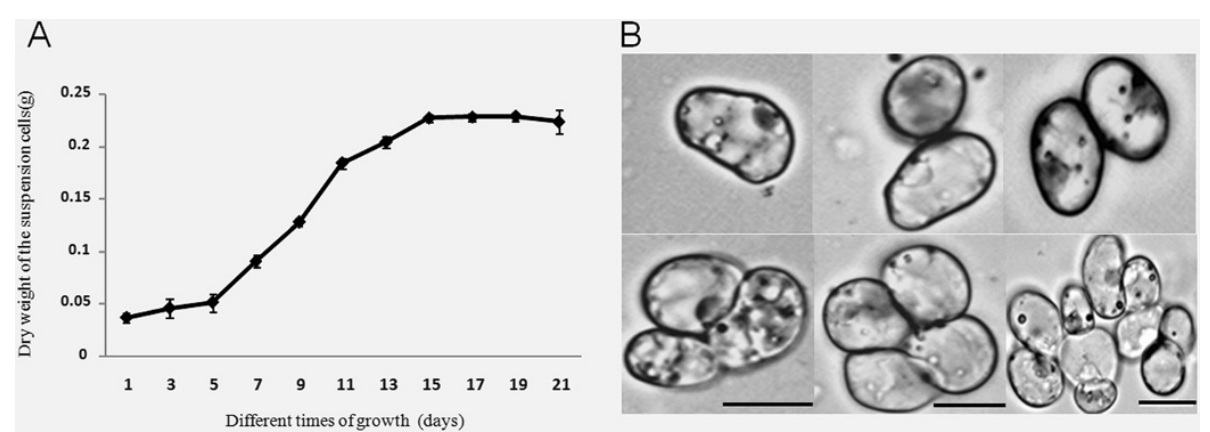

Figure 4 Growth curve of P.tenuiflora suspension-cultured cells. (A) Dry weight of the harvested $P$. tenuiflora suspension-cultured cells at different growth stages. (B) Image of $P$. tenuiflora suspension-cultured cells obtained using a microscope. Scale bar $=10 \mu \mathrm{m}$. The values represent the mean \pm standard errors $(n=3)$. 
that Agrobacterium concentration for genetic transformation should be kept as low as possible (an Agrobacterium concentration corresponding to $\mathrm{OD}_{600}=0.3$ was suitable for genetic transformation; data not shown). In addition, the length of co-culture during the transformation was also important for obtaining high transformation efficiency, as the bacteria were observed to be completely removed from the suspension cells after $3 \mathrm{~d}$ of co-culture (data not shown). Therefore, $3 \mathrm{~d}$ of co-culture was chosen as the optimum culturing time in order to obtain high transformation efficiency. Pandey et al. reported that optimal $\beta$-glucuronidase expression was observed in cumin embryos co-cultivated with an Agrobacterium cell suspension at an $\mathrm{OD}_{600}$ of 0.6 for $72 \mathrm{~h}$ [27], while the optimal transformation efficiency of suspensioncultured Glycyrrhiza inflata Batalin cells was achieved using an Agrobacterium suspension of an $\mathrm{OD}_{600}$ of 0.4 over $24 \mathrm{~h}$ of co-cultivation [22]. These results suggested that co-cultivating the lowest concentration of Agrobacterium possible with plant suspension-cultured cells for approximately $3 \mathrm{~d}$ could provide optimal conditions for achieving highly efficient transformation.

\section{Optimization of the concentrations of Kan, Cef, and AS}

The working concentrations of Kan and Cef were examined. Figure 5A shows that the dry weight of the suspension-cultured cells significantly decreased with increasing concentrations of Kan, and that the working Kan concentration of $\sim 75 \mathrm{mg} / \mathrm{L}$ was most appropriate for this study. Moreover, the dry weight of the suspension-cultured cells slightly decreased with increasing concentrations of Cef. However, since the growth inhibition at $200 \mathrm{mg} / \mathrm{L}$ Cef was only slightly reduced compared to that at $300 \mathrm{mg} / \mathrm{L} \mathrm{Cef}$ (Figure 5B), the optimum concentrations of Kan and Cef were determined to be $75 \mathrm{mg} / \mathrm{L}$ and $200 \mathrm{mg} / \mathrm{L}$, respectively.

AS is a commonly used agent affecting Agrobacteriummediated plant genetic transformation. To test the ASmediated effects on the Agrobacterium-mediated genetic transformation of $P$. tenuiflora suspension-cultured cells, 3-d-old AS-pretreated suspension cells were co-cultured with Agrobacterium at $\mathrm{OD}_{600}=0.5$ for $3 \mathrm{~d}$; non-pretreated cells were used as the control. A slight increase in the number of cell clusters from the AS-treated suspension cells on the solid medium was observed compared to that in the control (data not shown), suggesting that AS pretreatment could improve the efficiency of infection of $P$. tenuiflora suspension-cultured cells.

\section{Subcellular localization of proteins}

In order to carry out a proof of concept study for the use of stably transformed $P$. tenuiflora suspension-cultured cells in the analysis of the subcellular localization of proteins, the plasmid $p B I 121-E R-G F P$, encoding an ER-GFP fusion protein was used for genetic transformation. First, the calli were inoculated into MSPECH culture medium containing $2 \mathrm{mg} / \mathrm{L} \mathrm{2,4-D}$ and $30 \mathrm{~g} / \mathrm{L}$ sucrose ( $\mathrm{pH}$ 5.8) for $15 \mathrm{~d}$. After $3 \mathrm{~d}$, AS-pretreated cells were co-cultured with Agrobacterium at $\mathrm{OD}_{600} \approx 0.3$ for $3 \mathrm{~d}$, and the transgenic cell lines were selected on solid MSPECH medium containing $75 \mathrm{mg} / \mathrm{L}$ Kan and $200 \mathrm{mg} / \mathrm{L}$ Cef by observing them with a stereomicroscope (Olympus, SZX9, Japan). Green fluorescent cells were manually selected for subculture to obtain highly pure $P$. tenuiflora transgenic cell lines according to previously published protoplast isolation methods, with slight modifications for improvement [28-30]. After $5 \mathrm{~d}$ of cultivation, the GFP signals of the transgenic protoplasts were mainly concentrated on the plasma membrane and at the ER in association with the nuclear periphery, which is consistent with the subcellular localization pattern previously established for the PutAMT1;1 protein [17] (Figure 6A-B). Given the availability of stably transformed $P$. tenuiflora cell lines expressing the PutAMT1;1-GFP fusion protein, we plan to carry out further studies using subcellular fractionation and immunogold electron microscopy to determine the localization of this protein in its native cellular environment.

Taken together, the results presented herein indicate that the $P$. tenuiflora suspension-cultured cell system
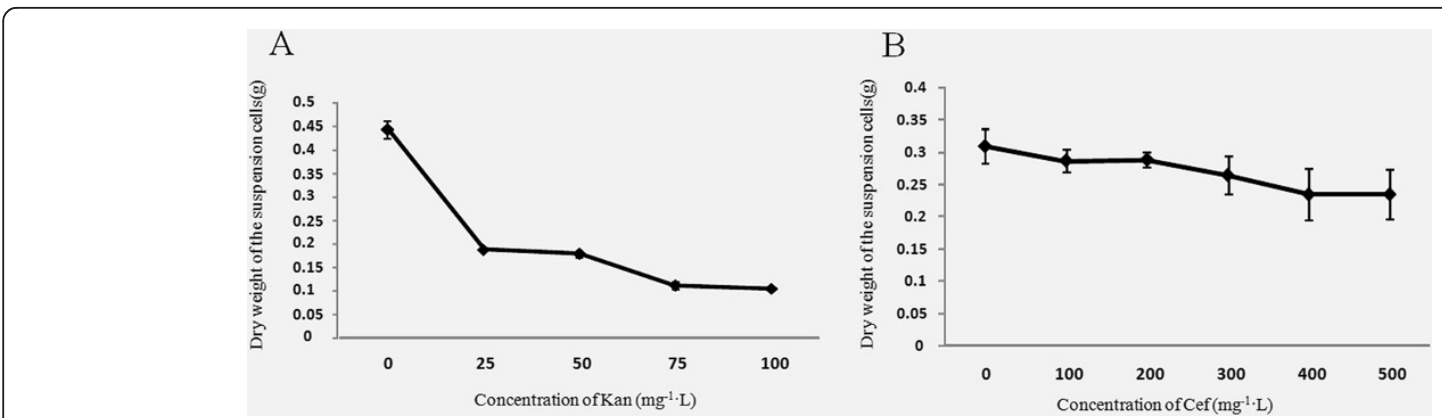

Figure 5 Test of the sensitivity of P.tenuiflora suspension-cultured cells against different concentrations of kanamycin (Kan) and cefotaxime (Cef). Dry weight of the harvested P. tenuiflora suspension-cultured cells at different concentrations of Kan (A) and Cef (B). The values represent the mean \pm standard errors $(n=3)$. 

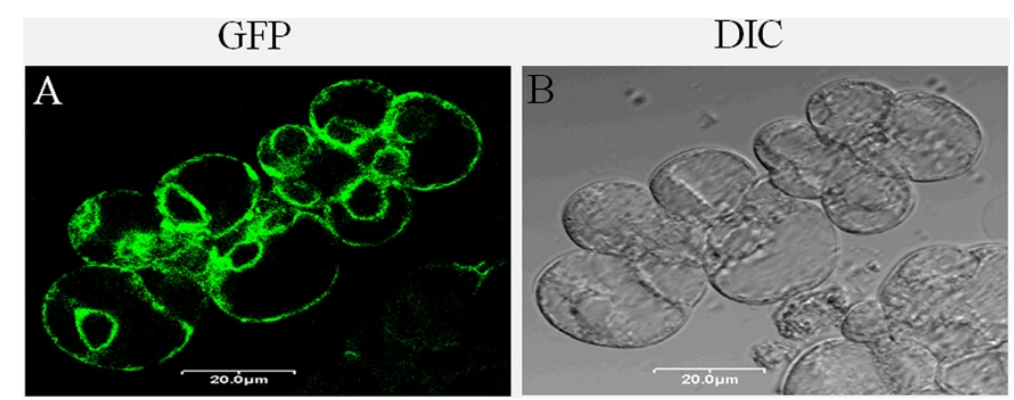

Figure 6 Subcellular localization of an endoplasmic reticulum-green fluorescent protein (ER-GFP) fusion protein in P. tenuiflora suspension-cultured cells. (A) GFP, (B) Differential interference contrast (DIC). All images were created using a laser-scanning confocal imaging system (Olympus Fluoview, FV500, Japan). GFP fluorescence was excited using an argon laser (488 nm). Scale bar = $20 \mu \mathrm{m}$.

could be successfully established and employed for protein subcellular localization analysis. Although previous studies reported that this approach may not be suitable for subcellular localization and other fluorescence-based analyses [31,32], we demonstrate that this optimized expression system based on $P$. tenuiflora suspension-cultured cells proved to be simple, reliable, and stable. Nevertheless, like all transformation methods relying on cells isolated from single organs without intervening regeneration of whole plants, this method can only be applied to examine the localization of proteins in cell compartments/structures that are present in the recipient cells. Therefore, the method is not suitable for studies requiring localization to the cell walls or plasmodesmata, for example, or to track protein movements in the context of organized tissues or organs. We note, however, that application of this method to other cell types deriving from different tissues such as the leaf, root, and inflorescence requires further validation to best ascertain the scope of applications of the method. In comparison to transient assays, our method is more labor-intensive and time-consuming, and thus does not lend itself readily to application in high-throughput studies [10]. However, the method does have an important advantage of providing homogeneous populations of transformed cells in virtually unlimited amounts for extended periods of time that can be used in all localization assays, which cannot otherwise be carried out on transiently transformed protoplasts owing to their complexity or particular technical requirements (e.g., cell fractionation, embedding and sectioning, immunolocalization $[33,34])$. Furthermore, we expect that our stable transformation method could be suitable for dynamically documenting protein re-localization through the different phases of the cell cycle or in response to environmental cues, although this was not directly tested in the present study. Most importantly, the fact that this method does not rely on whole plant regeneration makes it applicable to any non-model plant species lacking suitable regeneration protocols, which is a substantial advantage. As the method is based on simple, species-specific optimization steps of protocols that were previously developed for functional analyses in a relatively distantly related monocot species (rice), we expect that, with minor modifications, the method could be applied to several other non-model species from the Poaceae family.

\section{Conclusions}

We have developed a rapid and stable suspension-cultured cell system for non-model plants (i.e., those lacking suitable regeneration protocols) based on an Agrobacteriummediated approach. This method was successfully used for determining ER-GFP fusion protein subcellular localization in P. tenuiflora. Our method is simple and rapid, and is applicable to evaluating the localization of proteins only in cell compartments/structures that are present in the recipient cells.

\section{Abbreviations}

GFP: Green fluorescent protein; ER: Endoplasmic reticulum; MS: Murashige and Skoog; 2,4-days: 2,4-dichlorophenoxyacetic acid; 1/2 MS: Half concentration of regular MS; MSN: Contains 1/2 amount of ammonium nitrate of MS; MSK: Contains 1/2 amount of potassium nitrate; MSE: Contains additional $0.5 \mathrm{mg} / \mathrm{L}$ glutamic acid; MSP: Contains additional $0.5 \mathrm{~g} / \mathrm{L}$ proline; MSPE: Contains $0.5 \mathrm{mg} / \mathrm{L}$ glutamic acid and $0.5 \mathrm{~g} / \mathrm{L}$ proline; MSCH: Contains $0.6 \mathrm{~g} / \mathrm{L}$ casein acid hydrolysate; MSPECH: Contains $0.5 \mathrm{mg} / \mathrm{L}$ glutamic acid, $0.5 \mathrm{~g} / \mathrm{L}$ proline, and $0.6 \mathrm{~g} / \mathrm{L}$ casein acid hydrolysate; AS: Acetosyringone; Kan: Kanamycin; Cef: Cefotaxime; GUS: $\beta$-glucuronidase.

\section{Competing interests}

The authors declare that they have no competing interests.

\section{Authors' contributions}

$Y B, M Z$ and $S L$ designed the study. $Y B$ and $M Z$ performed the experiments and drafted the manuscript. BS conducted the statistical analysis. XZ prepared vectors. SL and TT supervised the study and critically revised the manuscript. All authors read and approved the final manuscript.

\section{Acknowledgements}

This work was supported by the Program for Changjiang Scholars and Innovative Research Team in University of China (PCSIRT), State Forestry Administration 948 Program of PR China (No. 2008429) and the Heilongjiang Provincial Program for Distinguished Young Scholars (JC200609) awarded to Shenkui Liu. Further support was provided by the Fundamental Research Funds for the Central Universities (No. DL13BAX13) awarded to Yuan-yuan Bu. The funders had no role in study design. We thank the Editage Corporation for providing the English editing service. 


\section{Author details}

${ }^{1}$ Key Laboratory of Saline-Alkali Vegetation Ecology Restoration in Oil Field (SAVER), Ministry of Education, Alkali Soil Natural Environmental Science Center (ASNESC), Northeast Forestry University, Hexing Road No. 26, Xiangfang District, Harbin City, Heilongjiang Province 150040, China. ${ }^{2}$ Asian Natural Environmenta Science Center (ASNESC), The University of Tokyo, Nishitokyo, Tokyo 188-0002, Japan.

Received: 12 January 2014 Accepted: 26 May 2014

Published: 5 June 2014

\section{References}

1. Bodén M, Hawkins J: Prediction of subcellular localization using sequence-biased recurrent networks. Bioinformatics 2005, 21(10):2279-2286

2. Adelfio A, Volpato $V$, Pollastri G: SCLpredT: Ab initio and homology-based prediction of subcellular localization by N-to-1 neural networks. Springerplus 2013, 2:502.

3. Liu L, Zhang Z, Mei Q, Chen M: PSI: a comprehensive and integrative approach for accurate plant subcellular localization prediction. PLoS One 2013, 8(10):e75826

4. Sheen J: Signal transduction in maize and Arabidopsis mesophyll protoplasts. Plant Physiol 2001, 127:1466-1475

5. Christou P: Strategies for variety-independent genetic transformation of important cereals, legumes and woody species utilizing particle bombardment. Euphytica 1995, 85:13-27.

6. Yang Y, Li R, Qi M: In vivo analysis of plant promoters and transcription factors by agroinfiltration of tobacco leaves. Plant J 2000, 22:543-551.

7. Ardie SW, Liu S, Takano T: Expression of the AKT1-type K(+) channel gene from Puccinellia tenuiflora, PutAKT1, enhances salt tolerance in Arabidopsis. Plant Cell Rep 2010, 29(8):865-874

8. Ardie SW, Xie L, Takahashi R, Liu S, Takano T: Cloning of a high-affinity K+ transporter gene PutHKT2;1 from Puccinellia tenuiflora and its functional comparison with OsHKT2;1 from rice in yeast and Arabidopsis. J Exp Bot 2009, 60(12):3491-3502.

9. Liu H, Zhang X, Takano T, Liu S: Characterization of a PutCAX1 gene from Puccinellia tenuiflora that confers $\mathrm{Ca}^{2+}$ and $\mathrm{Ba}^{2+}$ tolerance in yeast. Biochem Biophys Res Commun 2009, 383(4):392-396.

10. Marion J, Bach L, Bellec Y, Meyer C, Gissot L, Faure JD: Systematic analysis of protein subcellular localization and interaction using high-throughput transient transformation of Arabidopsis seedlings. Plant J 2008, 56(1):169-179.

11. Ogawa Y, Sakurai N, Oikawa A, Kai K, Morishita Y, Mori K, Moriya K, Fujii F, Aoki K, Suzuki H, Ohta D, Saito K, Shibata D: High-throughput cryopreservation of plant cell cultures for functional genomics. Plant Cell Physiol 2012, 53(5):943-952

12. Callard D, Axelos M, Mazzolini L: Novel molecular markers for late phases of the growth cycle of Arabidopsis thaliana cell-suspension cultures are expressed during organ senescence. Plant Physiol 1996, 112(2):705-715.

13. Mitsukawa N, Okumura S, Shirano Y, Sato S, Kato T, Harashima S, Shibata D: Overexpression of an Arabidopsis thaliana high-affinity phosphate transporter gene in tobacco cultured cells enhances cell growth under phosphate-limited conditions. Proc Natl Acad Sci U S A 1997, 94(13):7098-7102.

14. Uno Y, Furihata T, Abe H, Yoshida R, Shinozaki K, Yamaguchi-Shinozaki K Arabidopsis basic leucine-zipper transcription factors involved in an abscisic acid-dependent signal transduction pathway under drought and high-salinity conditions. Proc Natl Acad Sci U S A 2000, 97(21):11632-11637.

15. Takahashi S, Katagiri T, Hirayama T, Yamaguchi-Shinozaki K, Shinozaki K: Hyperosmotic stress induced a rapid and transient increase in inositol 1,4,5-trisphosphate independent of abscisic acid in Arabidopsis cell culture. Plant Cell Physiol 2001, 42(2):214-222.

16. Stolc V, Samanta MP, Tongprasit W, Sethi H, Liang S, Nelson DC, Hegeman A, Nelson C, Rancour D, Bednarek S, Ulrich EL, Zhao Q, Wrobel RL, Newman CS, Fox BG, Phillips GN Jr, Marklev JL, Sussman MR: Identification of transcribed sequences in Arabidopsis thaliana by using high-resolution genome tiling arrays. Proc Natl Acad Sci U S A 2005, 102(12):4453-4458.

17. Bu Y, Sun B, Zhou A, Zhang X, Lee I, Liu S: Identification and Characterization of a PutAMT1;1 Gene from Puccinellia tenuiflora. PLoS One 2013, 8(12):e83111.
18. Wang M, Yuan F, Hao H, Zhang Y, Zhao H, Guo A, Hu J, Zhou X, Xie CG: BolOST1, an ortholog of Open Stomata 1 with alternative splicing products in Brassica oleracea, positively modulates drought responses in plants. Biochem Biophys Res Commun 2013, 442(3-4):214-220.

19. Sasaki K, Christov NK, Tsuda S, Imai R: Identification of a novel LEA protein involved in freezing tolerance in wheat. Plant Cell Physiol 2013, in press.

20. Campanoni P, Sutter JU, Davis CS, Littlejohn GR, Blatt MR: A generalized method for transfecting root epidermis uncovers endosomal dynamics in Arabidopsis root hairs. Plant J 2007, 51:322-330.

21. Ozawa K, Takaiwa F: Highly efficient Agrobacterium-mediated transformation of suspension-cultured cell clusters of rice (Oryza sativa L.). Plant Sci 2010 179:333-337.

22. Li Y, Li S, Dong Y, Zhang Y, Fu C, Yu L: Stable transformation of suspension-cultured Glycyrrhiza inflata batalin cells with agrobacterium tumefaciens. Z Naturforsch C 2012, 67(11-12):603-610.

23. Kobayashi S, Abe N, Yoshida KT, Liu S, Takano T: Molecular cloning and characterization of plasma membrane- and vacuolar-type $\mathrm{Na}^{+} / \mathrm{H}^{+}$ antiporters of an alkaline-salt-tolerant monocot. Puccinellia tenuiflora. J Plant Res 2012, 125(4):587-594.

24. Wang SM, Zhao GQ, Gao YS, Tang ZC, Zhang CL: Puccinellia tenuiflora exhibits stronger selectivity for $\mathrm{K}^{+}$over $\mathrm{Na}^{+}$than wheat. J Plant Nutr 2004, 27:1841-1857

25. Peng YH, Zhu YF, Mao YQ, Wang SM, Su WA, Tang ZC: Alkali grass resists salt stress through high $\left[\mathrm{K}^{+}\right]$and an endodermis barrier to $\mathrm{Na}^{+}$. J Exp Bot 2004, 55:939-949.

26. Wang CM, Zhang JL, Liu XS, Li Z, Wu GQ, Cai JY, Flowers TJ, Wang SM: Puccinellia tenuiflora maintains a low $\mathrm{Na}+$ level under salinity by limiting unidirectional $\mathrm{Na}+$ influx resulting in a high selectivity for $\mathrm{K}+$ over Na+. Plant Cell Environ 2009, 32:486-496.

27. Pandey S, Mishra A, Patel MK, Jha B: An efficient method for agrobacterium-mediated genetic transformation and plant regeneration in cumin (cuminum cyminum L.). Appl Biochem Biotechnol 2013, 171(1):1-9.

28. Schirawski J, Planchais S, Haenni AL: An improved protocol for the preparation of protoplasts from an established Arabidopsis thaliana cell suspension culture and infection with RNA of turnip yellow mosaic tymovirus: a simple and eliable method. J Virol Methods 2000, 86(1):85-94.

29. Lee LY, Fang MJ, Kuang LY, Gelvin SB: Vectors for multi-color bimolecular fluorescence complementation to investigate protein-protein interactions in living plant cells. Plant Methods 2008, 4:24

30. Wu FH, Shen SC, Lee LY, Lee SH, Chan MT, Lin CS: Tape-Arabidopsis sandwich-A simpler Arabidopsis protoplast isolation method. Plant Methods 2009, 5:16

31. Zhang Y, Su J, Duan S, Ao Y, Dai J, Liu J, Wang P, Li Y, Liu B, Feng D, Wang J, Wang H: A highly efficient rice green tissue protoplast system for transient gene expression and studying light/chloroplast-related processes. Plant Methods 2011, 7(1):30.

32. Li JF, Park E, von Arnim AG, Nebenfuhr A: The FAST technique: a simplified Agrobacterium-based transformation method for transient gene expression analysis in seedlings of Arabidopsis and other plant species. Plant Methods 2009, 5:6.

33. Szymanski WG, Kierszniowska S, Schulze WX: Metabolic labeling and membrane fractionation for comparative proteomic analysis of Arabidopsis thaliana suspension cell cultures. J Vis Exp 2013, 79:e50535.

34. Marie-Laure F-G, Sophie P, Loïc F, Véronique G, Azeddine D: An improved chemical fixation method suitable for immunogold localization of green fluorescent protein in the Golgi apparatus of tobacco bright yellow (BY-2) cells. J Histochem Cytochem 2003, 51(7):931-940.

doi:10.1186/1472-6750-14-52

Cite this article as: Bu et al:: An efficient method for stable protein targeting in grasses (Poaceae): a case study in Puccinellia tenuiflora. BMC Biotechnology 2014 14:52 